\title{
Tele-medicine versus face-to-face consultation in Endocrine Outpatients Clinic during COVID-19 outbreak: a single-center experience during the lockdown period
}

\author{
F. Ceccato ${ }^{1,2} \mathbb{D} \cdot$ G. Voltan $^{1}$. C. Sabbadin ${ }^{1}$ - V. Camozzi ${ }^{1} \cdot$ I. Merante Boschin ${ }^{1,3} \cdot$ C. Mian ${ }^{1} \cdot$ V. Zanotto ${ }^{1} \cdot$ D. Donato $^{4}$. \\ G. Bordignon ${ }^{4}$ - A. Capizzi ${ }^{4}$ - G. Carretta ${ }^{4} \cdot$ C. Scaroni ${ }^{1}$
}

Received: 25 September 2020 / Accepted: 24 November 2020 / Published online: 23 December 2020

(c) The Author(s) 2020

\begin{abstract}
Context The COVID-19 outbreak in Italy is the major concern of Public Health in 2020: measures of containment were progressively expanded, limiting Outpatients' visit.

Objective We have developed and applied an emergency plan, tailored for Outpatients with endocrine diseases.

Design Cross-sectional study from March to May 2020.

Setting Referral University-Hospital center.

Patients 1262 patients in 8 weeks.

Interventions The emergency plan is based upon the endocrine triage, the stay-safe procedures and the tele-Endo. During endocrine triage every patient was contacted by phone to assess health status and define if the visit will be performed faceto-face (F2F) or by tele-Medicine (tele-Endo). In case of F2F, targeted stay-safe procedures have been adopted. Tele-Endo, performed by phone and email, is dedicated to COVID-19-infected patients, to elderly or frail people, or to those with a stable disease.

Main outcome measure To assess efficacy of the emergency plan to continue the follow-up of Outpatients.

Results The number of visits cancelled after endocrine triage (9\%) is lower than that cancelled independently by the patients $(37 \%, p<0.001)$; the latter reduced from 47 to $19 \%$ during the weeks of lockdown $(p=0.032) .86 \%$ of patients contacted by endocrine-triage received a clinical response (F2F and tele-Endo visits). F2F visit was offered especially to young patients; tele-Endo was applied to $63 \%$ of geriatric patients $(p<0.001)$, visits' outcome was similar between young and aged patients. Conclusions The emergency plan respects the WHO recommendations to limit viral spread and is useful to continue followup for outpatients with endocrine diseases.
\end{abstract}

Keywords Endocrine unit · COVID-19 - Telemedicine $\cdot$ Hub-spoke organization

F. Ceccato

filippo.ceccato@unipd.it

1 Endocrinology Unit, Department of Medicine DIMED, University-Hospital of Padova, European Reference Network On Rare Endocrine Conditions (endoERN) Center of Padova, Via Ospedale Civile, 105, 35128 Padova, Italy

2 Department of Neuroscience DNS, University of Padova, Padova, Italy

3 Department of Surgical Oncological and Gastroenterological Sciences (DiSCOG), University of Padova, Padova, Italy

4 Department of Directional Hospital Management, University-Hospital of Padova, European Reference Network On Rare Endocrine Conditions (endoERN) Center of Padova, Padova, Italy

\begin{tabular}{|c|c|}
\hline Abbreviatio & \\
\hline AOU & $\begin{array}{l}\text { University-Hospital (Azienda } \\
\text { Ospedale-Università) }\end{array}$ \\
\hline COVID 19 & Coronavirus Disease 2019 \\
\hline eCRF & electronic Case Report/Record Form \\
\hline $\mathrm{F} 2 \mathrm{~F}$ & Face-to-face \\
\hline FNA & Fine needle aspiration \\
\hline GP & General practitioner \\
\hline $\mathrm{HCP}$ & Health-care providers \\
\hline HW & Health workers \\
\hline NHS & National Health-care System \\
\hline SARS-CoV-2 & $\begin{array}{l}\text { Severe Acute Respiratory Syndrome } \\
\text { Coronavirus }\end{array}$ \\
\hline US & Ultrasound \\
\hline WHO & World Health Organization \\
\hline
\end{tabular}




\section{Introduction}

In early 2020, the world experienced the Severe Acute Respiratory Syndrome Coronavirus (SARS-CoV-2) infection, rapidly labelled as global pandemic by the World Health Organization (WHO) [1]. The clinical spectrum of Coronavirus Disease 2019 (COVID 19) ranges from asymptomatic carriers [2], to patients with mild/selflimiting respiratory tract illness, up to those with severe progressive pneumonia [3], multi-organ failure, and death $[4,5]$.

People affected by different endocrine diseases are facing their own disease and the risk of COVID-19 infection; however, the clinical impact of the SARS-CoV-2 in this subset of patients is not already kwon [6-10]. COVID19 treatment might induce endocrine complications, as adrenal insufficiency secondary to the high-dose glucocorticoid treatment, which is sometimes used in patients with severe disease $[11,12]$. SARS-CoV-2-related subacute thyroiditis may be an underestimated manifestation of COVID-19 [13], and adrenal infarction can represent a factor of poorer prognosis [14]. Recently, dexamethasone has been reported effective to reduce 28 -day mortality among patients receiving invasive mechanical ventilation or oxygen at randomization [15]. A direct effect on hypothalamic-pituitary-adrenal axis or thyroid cells was described during previous SARS outbreak in 2002-2003 $[16,17]$. Despite the aforementioned acute presentation, most of the common endocrine diseases (thyroid or adrenal autoimmunity, secondary hypertension or osteoporosis, pituitary/thyroid/adrenal tumours) are long-term conditions; therefore, increased awareness, motivation about diagnostic path and self-management are of paramount importance in affected patients [18-20].

First cases in Italy and in Veneto (one of the most SARS-CoV-2-affected area) were reported since the end of February [21]. Further clusters were identified, and measures of containment were progressively expanded, enforcing social distancing, isolation and quarantine of all positive cases and their relatives. Despite such procedures, at the time of this submission (October, 2020), COVID-19 achieved more or less 450,000 infections and 37,000 deaths in Italy (respectively, 38.000 and 2.300 in Veneto, data from the Italian National Institute of Health [22]). Moreover, Italy is approaching the second outbreak wave, as most of others European countries. The Italian Government superimposed the lockdown in March 2020: a redefinition of the rules generally applied to the Italian National Health-care System (NHS) forced us to change the organization of our Endocrine Outpatients clinic.

An implementation-oriented resilient NHS is characterized by the capability to develop new models/policies in case of unexpected event [23], as SARS-CoV-2 outbreak. Therefore, we had not only to face the COVID-19 infection, but also to change our usual approach at the Outpatient Clinic, from the traditional face-to-face (F2F) visit to new models, as tele-Medicine consultation: it can allow clinicians to maintain the doctor-patient relationship.

We have quickly developed a care pathway tailored for the Endocrine Outpatients Clinic in a biohazard scenario. We have collected the first results of its application during the weeks of lockdown to assess its adequacy.

\section{Materials and methods}

\section{The endocrine triage}

On March 8th, 2020, the Italian Government announced a new decree imposing the quarantine of 13 different municipalities in Northern Italy. Few days later (March, 11th), lockdown policies were applied to Italy. Regarding outpatients, only first visits suggested by the Emergency Department or by the General Practitioners (GPs) were allowed with F2F modality. First or follow-up visits dedicated to pregnancy or to patients with a neoplasm (thyroid or adrenal cancer, pituitary adenoma, neuro-endocrine tumours, parathyroid disease and their follow-up) could be performed, if social distancing was guaranteed.

Health-care providers (HCPs) in the Veneto Region are organized as a Hub-Spoke model [24]. University-Hospital (AOU, Azienda Ospedale-Università) of Padova is one of the European Reference Network for Rare Endocrine Disease (Endo-ERN) Center. Endocrine Outpatient Clinic covers all fields of endocrinology, from the first level as a spoke for the inhabitants of Padova, to the most complex cases requiring dedicated expertise and multi-disciplinary evaluation, as a hub centre for Italian patients. In our Endocrine Unit, first-level endocrinology (the spoke) is organized in 15 dedicated rooms every week, dedicated to all new referrals (new patients) or to the follow-up of thyroid autoimmune disease or nodules, metabolic diseases, gynaecological endocrinology and non-fractured osteoporosis. GPs, other Physicians or emergency department suggest patients' first-access. Follow-up visits are planned during the previous assessment. We have a dedicated Endocrine Service for pregnant women, with thyroid ultrasound (US) facility. Second-level Endocrinology (the hub) is divided in Neuroendocrinology, Adrenal Disease, Thyroid Disease, Gynaecological Endocrinology, Rare Diseases, Autoimmune Endocrinology, Osteoporosis and PTH disease.

Medical history is always available: clinical data are reported in the web-based database of the AOU Padova, used as an electronic Case Report/Record Form (eCRF). 
All visits must be scheduled by reservation: during COVID-19 outbreak, the reorganization of the outpatient clinic was necessary. To ensure the health of patients and health workers (HWs), we have developed the endocrine triage, reported in Fig. 1. The endocrine triage is a proactive measure, performed by phone and based upon a specific template that assisted the endocrinologist in making the decision between tele-Endo and F2F visit.

After the endocrine triage, the decision between F2F or tele-Medicine visit was recorded in an electronic sheet, shared in each room and available only for registered physicians/nurses. A dedicated phone number

Fig. 1 The "endocrine triage"

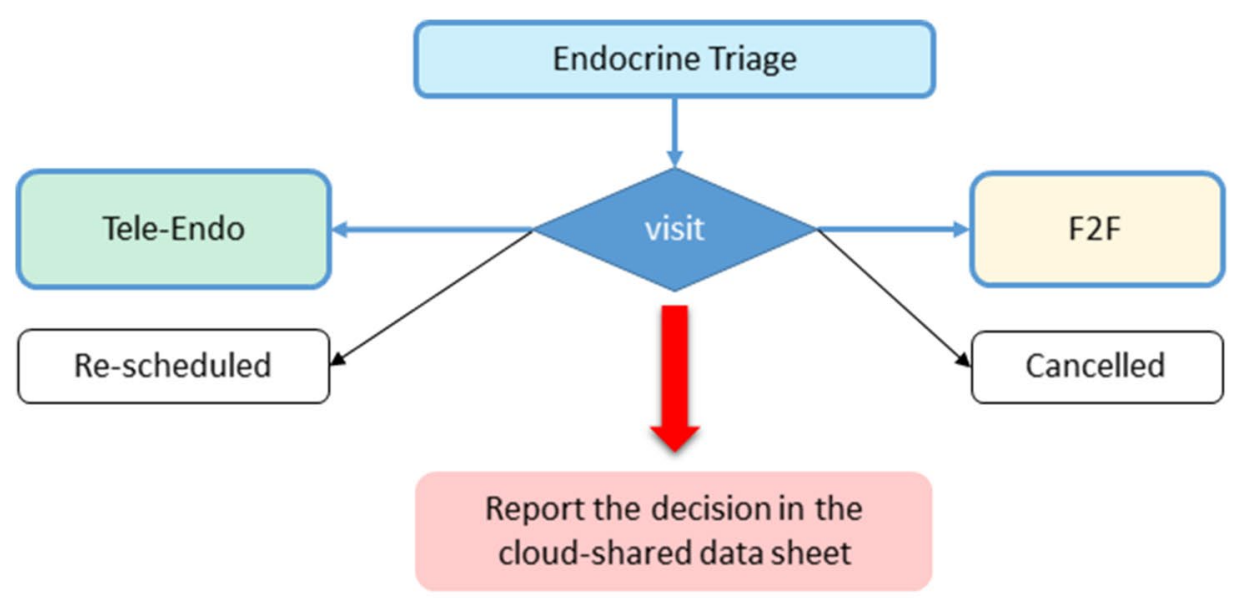

Telephone triage $\rightarrow$ call ALL PATIENTS

WHO: Endocrinologist, nurse

WHAT: evaluation between tele-Endo and F2F visit

WHEN: at least 5 days before the scheduled visit

\section{F2F visit}

WHO: Endocrinologist/resident + nurse

WHAT: stay safe procedure

WHEN: 1 visit every 30 minutes

HOW: 1 patient in the room and 1 in the waiting room

\section{Tele-Endo visit}

WHO: resident (ask to Endocrinologist in case of questions), nurse

HOW: use of data sheet in the cloud

WHEN: same visit previosuly scheduled as F2F

WHAT to indicate in the sheet

$\checkmark$ Personal data, phone number and email address

$\checkmark$ Patient send previous performed examinations via email

1. Call the patient

2. Collect clinical data, check health

3. Views and comments clinical reports

4. Decide the next visit

5. Schedule the next visit, blood examination and radiolgical evaluation (if provided)

6. Clinical response (digitally signed) and requests sent to the patient 
has been established, operated by a Physician and active h8.00-h18.00. Some of Endocrine HWs (nurses, residents or physicians) were temporarily relocated in the COVID-19 wards.

In case of F2F visit, the stay-safe procedures indicated in Table 1 have been adopted to reduce the risk of COVID-19 infection.

Thyroid US evaluations and fine needle aspiration (FNA) were subjected to a triage: those dedicated to known or suspected thyroid cancer were performed during lockdown weeks. An increased protection (in addition to the stay-safe procedures) was applied to the physician during the US/FNA procedure.

\section{Tele-medicine applied to endocrinology: tele-Endo}

To guide the Endocrinologist during the endocrine triage, a multiple-choice questionnaire (with yes/no answer) has been adopted. After phone-agreement with the patient, tele-Endo was proposed in case of at least one positive item among:

- Patient confined at home for COVID-19 infection (after hospitalization, asymptomatic or with mild symptoms) or quarantine, including their relatives.

- Follow-up visits;

- Age > 65 years;

- Clinical assessment considered by endocrinologist not absolutely necessary;

- Endocrine treatment started 6 months before;

- Recognized ability to use email (with the help of familymembers/caregivers if needed)

As depicted in Fig. 1, tele-Endo is planned before the scheduled visit appointment:

1. At least 5 working days before the visit, an Endocrinologist calls the patient, checking the health status (signs or symptoms related to COVID-19 infection and/or the endocrine disease). During the phone call, endocrine disease's related blood and radiological examinations, requested during the previous visit, are checked.

2. The decision between F2F visit and tele-Endo is indicated to the patient.

3. If the patients refused the visit, or if examinations have not been already performed, the appointment is cancelled or re-scheduled. To ensure that patients are not lost-to-follow up, a new prescription for an Endocrine visit (in the former case) or a novel appointment (in the latter case) is provided.

4. If the patient agrees to tele-Endo, all the medical reports have to be sent to a dedicated email address (if not available in the local eCRF or in the Fascicolo Sanitario Elettronico Regionale, FSEr).

5. During tele-Endo visit, the endocrinologist asks the patient detailed information regarding health status, assesses correct assumption of drugs and if necessary suggests modifications of the schedule, views and comments clinical reports, plans next visit.

6. The visit report form (digitally signed), with the prescription of next control and examinations, is sent to the patient's email. A digital version of the report is stored in the web-based service of the AUP of Padova, and is available for GPs in the web-based service of the Veneto region (FSEr).

Also, the communication with other primary-care centers (other spokes in Veneto) were co-ordinated by mail.

\section{Statistical analyses}

To understand the number of visits, as well as the application of our suggested protocol in the real-life of Endocrine Service, we collected the number of visits performed during the lockdown weeks, and we compared them with the number of visits performed in the same weeks in 2019 , calculating the difference (termed $\Delta^{2019-2020}$ ). We

Table 1 The "Stay-safe" procedures

\begin{tabular}{|c|c|}
\hline Action & Explanation \\
\hline Dedicated signage & $\begin{array}{l}\text { To ensure that patients understand the fixed route, the social distancing, the hands cleaning with dedicate gel and the } \\
\text { appropriate use of masks }\end{array}$ \\
\hline Social distancing & At least $1 \mathrm{~m}$, with dedicated place marked on the floor for chairs, desks and waiting people \\
\hline Visit duration & From $20-30 \mathrm{~min}$, to ensure sufficient time for the stay-safe procedures \\
\hline Nurse at entrance gate & $\begin{array}{l}\text { Checks body temperature in all patient with a Non-Contact Handheld Cutaneous Infra-Red Thermometer for Fever } \\
\text { Screening (avoid entrance if }>37.5^{\circ} \text { ), gives instructions for the path, use of hydroalcoholyc gel, rational use of Face } \\
\text { Mask (entry to rooms is prohibited in the absence of it) }\end{array}$ \\
\hline Definition of a fixed route & $\begin{array}{l}\text { All patients and caregivers (provided only for minors, elderly or disabled people) must enter from one door } \longrightarrow \text { they } \\
\text { are accepted (by a nurse) } \longrightarrow \text { rest in the waiting-room (one per room), then they enter into the Endocrine Room } \\
\text { when the previous patient has left it }\end{array}$ \\
\hline Room quick san & Cleaning the desk, computer screen and keyboard, examination bed with dedicated disinfectants (after every patient) \\
\hline
\end{tabular}


compared the rate and type of visits, the use of dedicated email, the adequate endocrine control (adapted to the specific disease and considered as a dichotomous variable yes/ no), the modification of the schedules of endocrine treatment and the time proposed for the next visit. We divided our data according to age of presentation and first-second level (spoke/hub) endocrinology.

All patients gave their consent; the study was conducted in accordance with the principles of the Declaration of Helsinki. The Ethics Committee of AUP of Padova approved the study (number 37907-2020). Clinical data reported in eCRF were collected anonymously.

This observational study was conducted in accordance with the Strengthening the Reporting of OBservational studies in Epidemiology (STROBE) guidelines for cohort, case-control, and cross-sectional studies [25].

Proportions and rates were calculated for categorical data; continuous data were reported as means and standard error. Groups were compared by chi-square test for categorical variables and by the student's $t$ test for quantitative variables. The database was managed and statistical analysis performed by SPSS 24 software package for Windows (2016, IBM-SPSS, Armonk, New York, USA). Significance level was set as a $p<0.05$ for all tests. All data analysed during this study are included the data repositories of the University of Padova (Research Data UniPD [26]).

\section{Results}

In Table 2, we have described the number and the type of visits performed during the weeks of lockdown, considering that the beginning of the second week of March (10th and 11 th) was still characterized by normal routine activity. Considering the third week of March (from 16 to $20^{\text {th }}$ ) the actual start of the endocrine triage, we observed that the number of patients that cancelled their visit without prior consultation by the endocrine triage decreased from 47 to $19 \%\left(y=0.0371 x-0.5231, R^{2}=0.7797, p=0.032\right.$, reported in Fig. 2). The number of visits cancelled after endocrine triage $(9 \%)$ is far lower than the proportion of visits cancelled by patients $(36.6 \%, p<0.001)$.

As depicted in Fig. 2, most of the patients contacted by endocrine-triage received a clinical response: the sum of visits performed combining F2F and tele-Endo modality ranged from 62 to $86 \%$ weekly. The F2F visits were strictly subjected to the "stay-safe procedures" and none of the employers in the Endocrine Outpatient Clinic (physicians, residents and nurses) have been infected. Notably, all HWs of the AOU of Padova underwent a routine molecular swab for SARS-CoV-2 every 3 weeks. Considering admission for SARS-CoV-2 infection in the AOU of Padova, three outpatients were hospitalized for COVID-19, one with pneumonia. During contact-tracing activity, none of the infection was related to the follow-up visit.

Table 2 Distribution of all patients managed with the "endocrine triage" during the weeks of lockdown

\begin{tabular}{|c|c|c|c|c|c|c|c|c|c|}
\hline Week & Total patients & $\mathrm{F} 2 \mathrm{~F}$ & Tele-endo & $\begin{array}{l}\text { Total per- } \\
\text { formed }\end{array}$ & Re-scheduled & Cancelled & First visits & $\begin{array}{l}\text { Follow-up } \\
\text { visits }\end{array}$ & $\Delta^{2019-2020}$ \\
\hline March, 11-13 & 101 & $64(66.7 \%)$ & $17(17.7 \%)$ & $81(84.4 \%)$ & $11(8.2 \%)$ & $8(8.3 \%)$ & $16(19.8 \%)$ & $65(80.2 \%)$ & $\begin{array}{r}-43(- \\
30.9 \%)\end{array}$ \\
\hline March, 16-20 & 155 & $49(33.1 \%)$ & $78(53.1 \%)$ & $127(86.1 \%)$ & $16(6.4 \%)$ & $12(8.2 \%)$ & $27(21.3 \%)$ & $100(78.7 \%)$ & $\begin{array}{r}-132(- \\
47.3 \%)\end{array}$ \\
\hline March, 23-27 & 164 & $15(9.2 \%)$ & $105(66.3 \%)$ & $120(75.5 \%)$ & $31(16.2 \%)$ & $13(8.1 \%)$ & $19(15.8 \%)$ & $101(84.2 \%)$ & $\begin{array}{r}-121(- \\
43.4 \%)\end{array}$ \\
\hline $\begin{array}{c}\text { March, 30- } \\
\text { April, } 04\end{array}$ & 168 & $15(9 \%)$ & $107(65.1 \%)$ & $122(74 \%)$ & $37(20.4 \%)$ & $9(5.5 \%)$ & $18(14.8 \%)$ & $104(85.2 \%)$ & $\begin{array}{r}-115(- \\
41.2 \%)\end{array}$ \\
\hline April, 6-10 & 169 & $10(5.9 \%)$ & $98(58.0 \%)$ & $108(63.9 \%)$ & $42(24.9 \%)$ & $19(11.2 \%)$ & $10(9.3 \%)$ & $98(90.7 \%)$ & $\begin{array}{r}-110(- \\
39.4 \%)\end{array}$ \\
\hline April, 14-17 & 146 & $26(18.3 \%)$ & $61(43.3 \%)$ & $87(61.6 \%)$ & $44(28 \%)$ & $15(10.7 \%)$ & $13(14.9 \%)$ & $74(85.1 \%)$ & $\begin{array}{r}-75(- \\
34.9 \%)\end{array}$ \\
\hline April, 20-24 & 178 & $33(18.8 \%)$ & $83(47.2 \%)$ & $116(65.9 \%)$ & $39(21.0 \%)$ & $23(13.1 \%)$ & $7(6.0 \%)$ & $99(85.3 \%)$ & $\begin{array}{r}-103(- \\
36.9 \%)\end{array}$ \\
\hline April, 27-30 & 181 & $58(33.1 \%)$ & $73(42 \%)$ & $131(75 \%)$ & $37(17.5 \%)$ & $13(7.5 \%)$ & $12(9.2 \%)$ & $119(90.8 \%)$ & $\begin{array}{r}-41(- \\
19.1 \%)\end{array}$ \\
\hline Mean & 156 & $34(24.4 \%)$ & $78(49.1 \%)$ & $112(73.5 \%)$ & $30(17.3 \%)$ & $14(9 \%)$ & $15(13.9 \%)$ & $95(85.1 \%)$ & $\begin{array}{r}-92(- \\
36.6 \%)\end{array}$ \\
\hline
\end{tabular}

10-11/03 still normal activity at the endocrine service; 13/04: service close for Easter Monday; 01/05: service close for Labor Day. $\Delta^{2019-2020}$ : difference between the considered week of lockdown and the same week in 2019 
Fig. 2 Distribution of all visits, according to the decision during the endocrine triage, in the weeks of lockdown

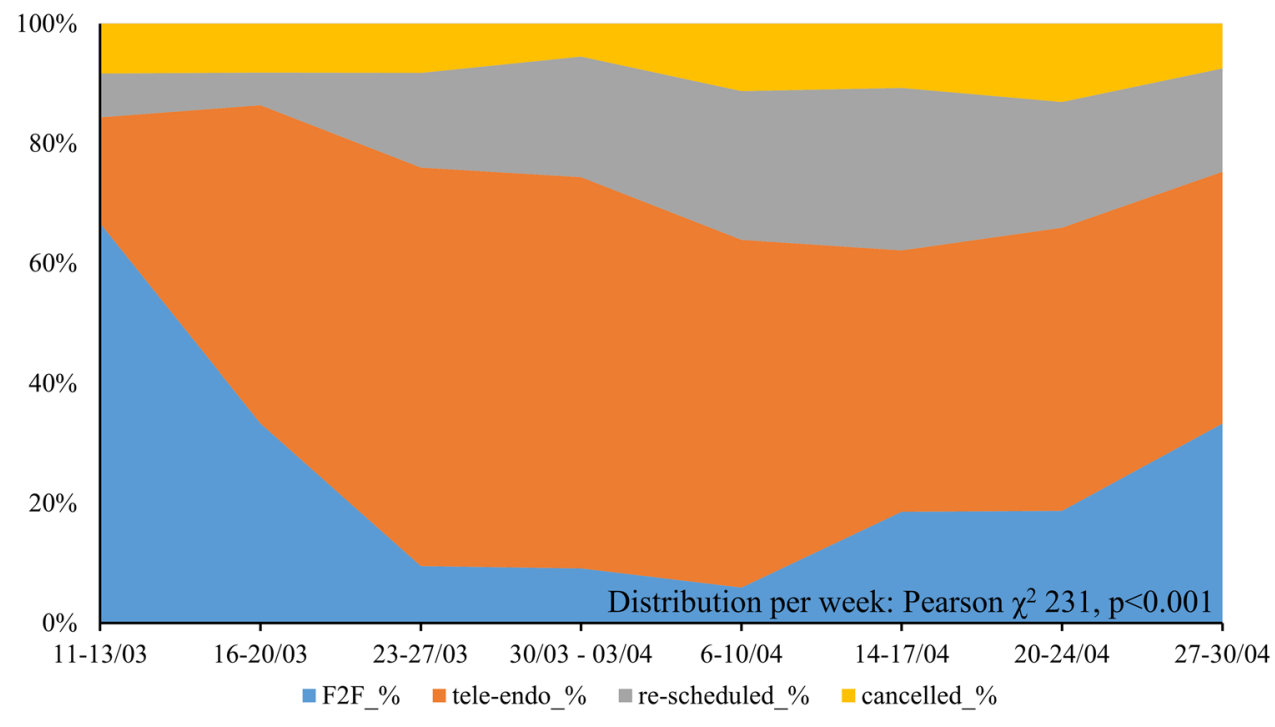

Overall, 369 patients (31.8\%) contacted by the endocrine triage were $\geq 65$ years of age. According to the previously reported criteria, F2F visit was offered especially to young patients, while tele-Endo was applied to $63.4 \%$ of patients with $\geq 65$ years $(p<0.001)$. The number of re-scheduled or cancelled visits was reduced in geriatric patients. Use of dedicated email, adequate endocrine control and modification of the endocrine treatment were similar in the two classes of age ( $<$ or $\geq 65$ years), as reported in Table 3. Moreover, the time proposed for the next visit was similar between F2F and tele-Endo visit ( $7.5 \pm 7$ vs. $8.2 \pm 6.2$ months, $p=0.605$ ).

In Fig. 3, we summarized the endocrine-triage applied to the second-level endocrinology. The number of performed visits (either F2F or tele-Endo) was similar according to different endocrine diseases, however, most of the patients with adrenal insufficiency were re-scheduled, because of their disease-related high-risk during COVID-19.

During the 8 weeks of lockdown, after the dedicated endocrine triage 114 thyroid ultrasound (US) evaluations have been performed ( $82 \%$ female, mean age $52 \pm 15$ years, $\left.\Delta^{2019-2020}-80 \%\right)$. Overall, 46 were follow-up US for differentiated thyroid cancer, 36 for thyroid nodes or multinodular goitre, 16 for new-onset hyperthyroidism. 27 FNA were performed.

\section{Discussion}

In 2020, the COVID-19 outbreak presented a significant impact in all NHSs, because thousands of patients with severe complications were hospitalized [1, 3, 4]. On the other hand, the larger part of SARS-CoV-2-infected patients presented with mild symptoms or are asymptomatic carriers [2], increasing the risk in Outpatients Clinic. Therefore, an effort in the organization of NHSs had to be performed, in order to reduce the risk of infection for patients and HWs [7], and to continue the management of long-term chronic conditions, as endocrine diseases. Little by little that the lockdown rules were imposed in the middle of March, we have prepared in few days an emergency plan, suitable for routine clinical practice, able to respond to the health requests of patients and to minimize the spread of the infection. Notably, in this paper, we described our experience with the first application of the emergency plan, reporting
Table 3 Distribution of patients according to the age of presentation

\begin{tabular}{llll}
\hline & Age at visit $<65$ years & Age at visit $\geq 65$ years & $p$ \\
\hline F2F $(n=269)$ & $210(78.1 \%)$ & $59(21.9 \%)$ & $<0.001$ \\
Tele-endocrinology $(n=622)$ & $388(62.4 \%)$ & $234(37.6 \%)$ & \\
Re-scheduled $(n=157)$ & $118(75.2 \%)$ & $39(24.8 \%)$ & \\
Cancelled $(n=112)$ & $75(67 \%)$ & $37(33 \%)$ & 0.231 \\
First visits $(n=159)$ & $115(72.3 \%)$ & $44(27.7 \%)$ & \\
Follow-up visits $(n=1001)$ & $676(67.5)$ & $325(32.5 \%)$ & 0.535 \\
Use of dedicated email & $276 / 599(46.1 \%)$ & $141 / 292(48.3 \%)$ & 0.152 \\
Adequate disease control & $393(66.8 \%)$ & $179 / 289(61.9 \%)$ & 0.188 \\
Modification of treatment & $200 / 588(34 \%)$ & $111 / 288(38.5 \%)$ & \\
\hline
\end{tabular}


Fig. 3 Distribution of all visits after endocrine triage, according to the different setting

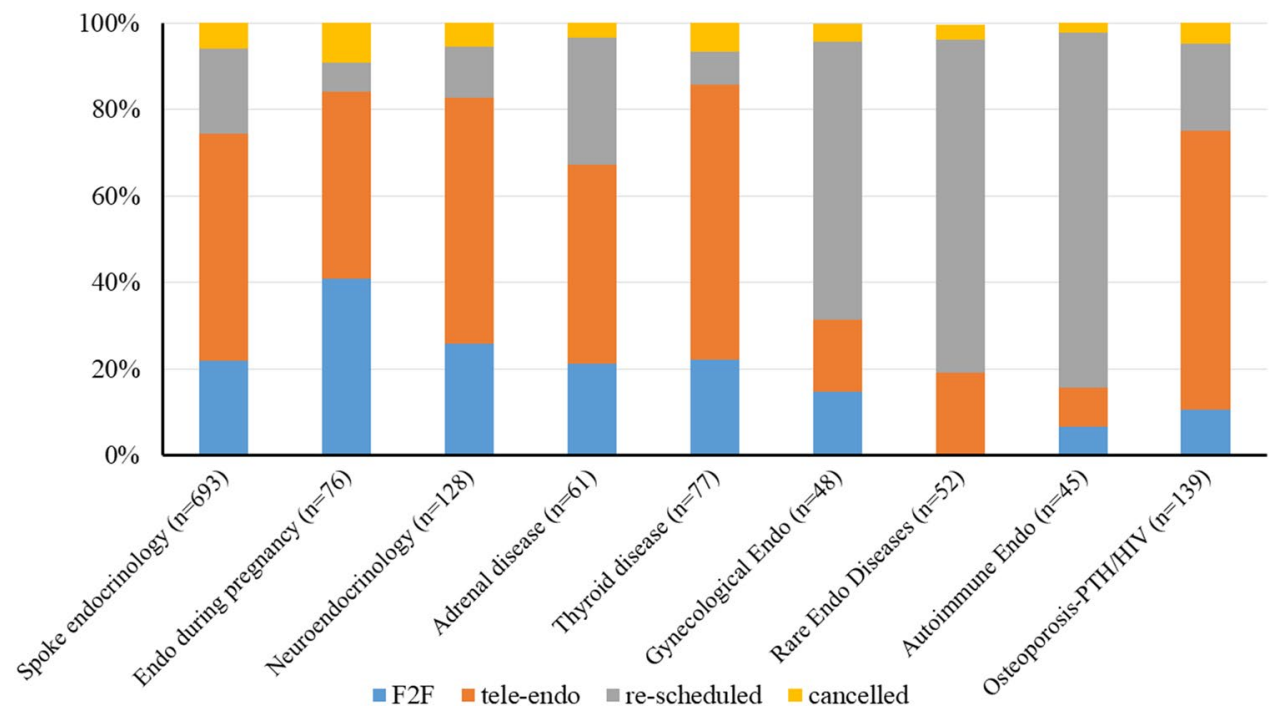

the clinical activities during the lockdown weeks, based upon the endocrine triage, the stay-safe procedures and the tele-Endo consultations. Therefore, the design of this paper is not that of a trial or a case-control group.

The follow-up of patients with chronic endocrine diseases is of outmost importance to reduce/prevent comorbidities, particularly in those assuming a long-term treatment. Therefore, one of our aim was to limit the cancellation of visits. We have decided to propose a proactive approach: to call each patient before his/her access into the Endocrine Clinic, which takes place by reservation. In order to reduce the communication gap between patients and endocrinologists, we have implemented the general helpline for endocrine emergencies phone number and institutional email. The $\Delta^{2019-2020}$ is the number of patients that cancelled their visit without a previous consultation through the endocrine triage, therefore, those who did not receive an adequate counselling. In the first weeks of lockdown, the number of visits that the patients decided to cancel by themselves was high, while it progressively decreased from March to April, thanks to the application of endocrine triage model. In case of F2F visit, the stay-safe procedures have been adopted to reduce the viral spread: dedicated signage of the rooms, social distancing, dedicated nurse, temperature control and the rational use of face mask. At the end of each visit, a quick sanitization of the room was planned. Endocrine triage was useful also for first visits that have been rescheduled, because a consultation with an endocrinologist is helpful to suggest the correct time to postpone the visit, according to the disease. To conclude, one of the principal results of endocrine triage is that the number of patients' cancellation of their visit reduced during time, according to the increased use of endocrine triage and tele-Endo. This approach is also useful to limit the number of re-scheduled visits, reducing the overload of the NHSs in the next months. In a high-risk scenario, we observed that our approach (based upon phone triage and tele-medicine) was useful to continue the follow-up of chronic patients.

Tele-Endo visit was considered after a tailored and careful selection of patients, at least 5 working days before the scheduled visit. After the patient's agreement to the new setting of assessment, all the medical reports suggested during the previous visit were sent to the dedicated email. The tele-Endo visit was scheduled at the same time than the previous visit planned before COVID-19 outbreak. During tele-Endo, the Endocrinologist asks the patient detailed data regarding health status, checks and comments the medical reports, suggests the modification of the treatment and plans next visit. Then, the digitally signed report form with all the prescriptions is prepared and sent to the patient's email. Three quarters of the over a thousand patients that had been contacted by the Endocrine Triage received an updated clinical response regarding their endocrine disease, considering the sum of F2F and tele-Endo visits. We paid a particular attention to those patients with adrenal insufficiency, since they are at high risk [27]. Most of them (and their relatives) are continuously educated to self-manage the risk of an adrenal crisis, by our Endocrinologists and nurses. Moreover, they can contact our Endocrine Clinic by email or phone in case of critical illness to obtain updated information regarding the management of adrenal crisis, including the modification of their glucocorticoid substitutive therapy. The endocrine triage for patients with adrenal insufficiency included also a remind of the "sick-days rules", because initial symptoms of COVID-19 disease (fatigue, malaise, gastrointestinal symptoms, and diarrhoea) are common to those observed in patients with adrenal insufficiency [28] as a consequence of an insufficient substitutive treatment. Tele-Endo was particularly useful in elderly patients with osteoporosis, or those with a secreting pituitary adenoma under medical treatment (prolactinomas, acromegaly and so 
on). Patients with thyroid dysfunction (auto-immune, hypoor hyperthyroidism) benefit from tele-Endo to modify their chronic medical therapy and to ensure a sufficient supply of medication, especially considering the correct titration of anti-thyroid drug, or thyroid treatment during pregnancy, as recently recommended [29].

Tele-Endo resulted a novel measure; however, in our opinion it could be used also after the outbreak, to limit the access to the HCPs. Tele-Endo could be considered to save time in situation of inappropriate health resources, or in view of reducing the geographical distances to the hub, or to save the loss of working hours for employees. In the normal context of everyday clinical practice, a F2F visit is better than a tele-medicine consultation, and the latter can substitute the former only in selected cases, as the renewal of prescriptions for chronic treatment. During tele-medicine visit, physical examinations (as thyroid palpation) is not feasible; moreover, evaluations of anthropometric parameters (weight, height, blood pressure) and data collections for clinical study could be biased by the patient, with possible negative impact on diagnosis, prognosis and clinical studies.

Elderly patients resulted at higher risk for COVID-19 [30]. On the whole, in the 8 weeks of lockdown, $31.8 \%$ of those contacted by endocrine triage were $\geq 65$ years of age: tele-Endo was applied in more than $60 \%$ of their visits. The use of dedicated email, adequate endocrine control and modification of the endocrine treatment during the tele-Endo visit was similar in subgroups of patients, irrespective of age of presentation. The number of re-scheduled or cancelled visits was reduced in geriatric patients after the endocrinetriage. To conclude, our suggested pathway seems confident also for patients $\geq 65$ years of age; however, a dedicated study should be considered.

The infective risk is not a minor concern for patients and HWs [31-33], first of all because the patients with an Endocrine conditions could be an asymptomatic carrier [2]. However, all HWs of the AOU of Padova underwent a routine molecular swab for SARS-CoV-2 every 3 weeks, and nowadays none of those working in the Endocrine Outpatient Service is positive. A reduced number of our patients were hospitalized for COVID-19 disease.

Our emergency plan has been developed in few days, and tested in few weeks. Notably, a request for authorization of tele-medicine was submitted from the Italian Society of Endocrinology to the Italian National Institute of Health (Istituto Superiore di Sanità, ISS) on April 29, receiving a positive reply on June 30 [34]. Dedicated platforms and data protection are suggested by the ISS. Since the end of 2019, in Veneto all the medical reports (either from NHS or private health system) as well as the images are reported in the FSEr, a web-based platform dedicated to the storage of medical data (data protection is guaranteed according to the European General Data Protection Regulation- GDPR
[35]). Since July, in the AOU of Padova, we can use a dedicated video-platform, where patients can deposit all medical reports in a virtual desktop (available 7 days before the telemedicine visit). High-quality image recorded in the FSEr are available in such platform, patients and physicians can communicate with a camera, and a protected connection with the eCRF of the HCP is used to write the medical reports and send them to the patient.

The endocrine-triage and tele-Endo approaches are not based on systematic reviews or meta-analysis, because there is no evidence on how to adopt endocrine care in times of a health crisis as this outbreak was. Moreover, each plan should be tailored to specific countries, because NHSs could be public, private or mixed. Italy was one of the first severely affected countries in Europe, and Veneto one of those with the higher COVID-19 load, where the containment measures have been applied earlier. During the application of our model, we have noticed some suggestions to improve our clinical practice, not only during an emergency scenario. First, we used phone call for tele-Endo; in the era of connectivity, our Stakeholders should encourage the use of web-based applications that consider patients' smartphone camera. Moreover, each HCP or region use a web-based system to store data (as FSEr in Veneto); however, they are not connected each other and this represents an issue especially in a hub centre dedicated to rare diseases living in a diffuse geographical area, that performed different biochemical/ radiological examinations in different HCPs.

Careful surveillance strategies proposed by Government and HCPs are mandatory to reduce further clusters. We have decided to continue the "stay-safe" procedures, as well as the endocrine triage for selected patients (adrenal insufficiency, hypercortisolism, age $\geq 65$ years). We think that our proposed proactive pathway can be really valuable in helping physicians to face circumstances that have not met before.

Our work presents several limitations. First, we do not have a clear research question: we can only propose a description of our routine clinical activity during the outbreak. Therefore, it lacks academic and scientific rigour, because a control group is not feasible.

There is little evidence available on the effectiveness of the Outpatient Service re-organization during a pandemic outbreak. Our strategies were effective in optimizing the spread of the virus (limiting the number of F2F visits) and in continuing the follow-up for patients with chronic endocrine disorders. Our model is far from perfection; however, we managed to give a clinical answer to $\approx 80 \%$ of patients. More time is needed to verify if our model is effective in the long term, but in the short term, we have combined the social distancing with the health of our patients.

Acknowledgements The authors are grateful to all residents in Endocrinology and Metabolism (Lizzul L., Costantini G., Tresso S., Pinelli 
S., Selmin E., Benvenuti T., Falaguasta D., Carducci S., Zhu YH., Piva I., Tizianel I., Vedolin CK., Mondin A., Ferretto S.), to PhD students (Barbot M., Manso J., Censi S.) and to all our Nurses (Lion A., Siviero A., Kucmierz EZ., Saccuman L., Morato M., Facchinato M., Toniato O., Gabbatore S.)

Funding Open access funding provided by Università degli Studi di Padova within the CRUI-CARE Agreement. This study did not receive any specific grant from any funding agency in the public, commercial or not-for-profit sector.

Data availability statement All data analysed during this study are included in this published article or in the data repositories listed in References.

\section{Compliance with ethical standards}

Conflict of interest All authors declare that they have no conflicts of interest that might be perceived as influencing the impartiality of the reported research.

Ethical approval All procedures followed were in accordance with the ethical standards of the responsible committee on human experimentation (institutional: Comitato Etico per la Sperimentazione Scientifica, CESC of Padova University Hospital) and with the Helsinki Declaration of 1964 and later versions.

Informed consent Informed consent has been obtained.

Open Access This article is licensed under a Creative Commons Attribution 4.0 International License, which permits use, sharing, adaptation, distribution and reproduction in any medium or format, as long as you give appropriate credit to the original author(s) and the source, provide a link to the Creative Commons licence, and indicate if changes were made. The images or other third party material in this article are included in the article's Creative Commons licence, unless indicated otherwise in a credit line to the material. If material is not included in the article's Creative Commons licence and your intended use is not permitted by statutory regulation or exceeds the permitted use, you will need to obtain permission directly from the copyright holder. To view a copy of this licence, visit http://creativecommons.org/licenses/by/4.0/.

\section{References}

1. Huang C, Wang Y, Li X et al (2020) Clinical features of patients infected with 2019 novel coronavirus in Wuhan, China. Lancet 395(10223):497-506. https://doi.org/10.1016/S0140 $-6736(20) 30183-5$

2. Bai Y, Yao L, Wei T et al (2020) Presumed asymptomatic carrier transmission of COVID-19. JAMA 323(14):1406. https://doi. org/10.1001/jama.2020.2565

3. Wang D, Hu B, Hu C et al (2020) Clinical characteristics of 138 hospitalized patients with 2019 novel coronavirus-infected pneumonia in Wuhan, China. JAMA 323(11):1061. https://doi. org/10.1001/jama.2020.1585

4. Phua J, Weng L, Ling L et al (2019) Intensive care management of coronavirus disease 2019 (COVID-19): challenges and recommendations. Lancet Respir Med. https://doi.org/10.1016/S2213 $-2600(20) 30161-2$
5. Shi Y, Wang Y, Shao C et al (2020) COVID-19 infection: the perspectives on immune responses. Cell Death Differ 27(5):14511454. https://doi.org/10.1038/s41418-020-0530-3

6. Isidori AM, Arnaldi G, Boscaro M et al (2020) COVID-19 infection and glucocorticoids: update from the Italian Society of Endocrinology Expert Opinion on steroid replacement in adrenal insufficiency. J Endocrinol Invest. https://doi.org/10.1007/s4061 8-020-01266-w

7. Puig-Domingo M, Marazuela M, Giustina A (2020) COVID-19 and endocrine diseases. A statement from the European Society of Endocrinology. Endocrine 68(1):2-5. https://doi.org/10.1007/ s12020-020-02294-5

8. Arlt W, Baldeweg SE, Pearce SHS, Simpson HL (2020) Endocrinology in the time of COVID-19: management of adrenal insufficiency. Eur J Endocrinol. https://doi.org/10.1530/EJE-20-0361

9. Newell-Price J, Nieman L, Reincke M, Tabarin A (2020) Endocrinology in the time of COVID-19: management of Cushing's syndrome. Eur J Endocrinol. https://doi.org/10.1530/EJE-20-0352

10. Fleseriu M, Karavitaki N, Dekkers OM (2020) Endocrinology in the time of COVID-19: management of pituitary tumours. Eur J Endocrinol. https://doi.org/10.1530/EJE-20-0473

11. Scaroni C, Armigliato M, Cannavò S (2020) COVID-19 outbreak and steroids administration: are patients treated for Sars-Cov-2 at risk of adrenal insufficiency? J Endocrinol Invest. https://doi. org/10.1007/s40618-020-01253-1

12. Ferraù $F$, Ceccato $F$, Cannavò $S$, Scaroni C (2020) What we have to know about corticosteroids use during Sars-Cov-2 infection. J Endocrinol Invest. https://doi.org/10.1007/s40618-020-01384-5

13. Brancatella A, Ricci D, Cappellani D et al (2020) Is subacute thyroiditis an underestimated manifestation of SARS-CoV-2 infection? Insights from a case series. J Clin Endocrinol Metab. https ://doi.org/10.1210/clinem/dgaa537

14. Leyendecker P, Ritter S, Riou M et al (2020) Acute adrenal infarction as an incidental CT finding and a potential prognosis factor in severe SARS-CoV-2 infection: a retrospective cohort analysis on 219 patients. Eur Radiol. https://doi.org/10.1007/s00330-02007226-5

15. RECOVERY Collaborative Group, Horby P, Lim WS et al (2020) Dexamethasone in hospitalized patients with Covid-19 preliminary report. N Engl J Med. https://doi.org/10.1056/NEJMoa2021 436

16. Leow MK-S, Kwek DS-K, Ng AW-K, Ong K-C, Kaw GJ-L, Lee LS-U (2005) Hypocortisolism in survivors of severe acute respiratory syndrome (SARS). Clin Endocrinol (Oxf) 63(2):197-202. https://doi.org/10.1111/j.1365-2265.2005.02325.x

17. Wei L, Sun S, Xu C et al (2007) Pathology of the thyroid in severe acute respiratory syndrome. Hum Pathol 38(1):95-102. https:// doi.org/10.1016/j.humpath.2006.06.011

18. Chatterjee S, Davies MJ, Heller S, Speight J, Snoek FJ, Khunti K (2018) Diabetes structured self-management education programmes: a narrative review and current innovations. Lancet Diabetes Endocrinol 6(2):130-142. https://doi.org/10.1016/S2213 -8587(17)30239-5

19. Glynn LG, Murphy AW, Smith SM, Schroeder K, Fahey T (2010) Self-monitoring and other non-pharmacological interventions to improve the management of hypertension in primary care: a systematic review. Br J Gen Pract 60(581):e476-e488. https://doi. org/10.3399/bjgp10X544113

20. Gai QY, Lv H, Li YP, Fu QM, Li P (2020) Education intervention for older adults with osteoporosis: a systematic review. Osteoporos Int 31(4):625-635. https://doi.org/10.1007/s00198-01905166-5

21. Spiteri G, Fielding J, Diercke M et al (2020) First cases of coronavirus disease 2019 (COVID-19) in the WHO European Region, 
24 January to 21 February 2020. Eurosurveillance. https://doi. org/10.2807/1560-7917.ES.2020.25.9.2000178

22. Ministero della Salute-Italia. http://www.salute.gov.it/portale/ nuovocoronavirus/homeNuovoCoronavirus.jsp?lingua=english. Accessed 22 Oct 2020

23. Nuzzo JB, Meyer D, Snyder M et al (2019) What makes health systems resilient against infectious disease outbreaks and natural hazards? Results from a scoping review. BMC Public Health 19(1):1310. https://doi.org/10.1186/s12889-019-7707-z

24. Elrod JK, Fortenberry JL (2017) The hub-and-spoke organization design: an avenue for serving patients well. BMC Health Serv Res 17(Suppl 1):457. https://doi.org/10.1186/s12913-017-2341-x

25. von Elm E, Altman DG, Egger M et al (2008) The Strengthening the Reporting of Observational Studies in Epidemiology (STROBE) statement: guidelines for reporting observational studies. J Clin Epidemiol 61(4):344-349. https://doi.org/10.1016/j. jclinepi.2007.11.008

26. Ceccato F (2020) Tele-endo during COVID-19 outbreak in Padova. Res Data Unipd. https://doi.org/10.25430/researchda ta.cab.unipd.it.00000357

27. Husebye ES, Allolio B, Arlt W (2014) Consensus statement on the diagnosis, treatment and follow-up of patients with primary adrenal insufficiency. J Intern Med. https://doi.org/10.1111/ joim. 12162

28. Isidori AM, Pofi R, Hasenmajer V, Lenzi A, Pivonello R (2020) Use of glucocorticoids in patients with adrenal insufficiency and COVID-19 infection. Lancet Diabetes Endocrinol 8(6):472-473. https://doi.org/10.1016/S2213-8587(20)30149-2

29. Boelaert K, Visser WE, Taylor PN, Moran C, Leger J, Persani L (2020) Endocrinology in the time of COVID-19: management of hyper- and hypo- thyroidism. Eur J Endocrinol. https://doi. org/10.1530/EJE-20-0445

30. Clarfield AM, Dwolatzky T, Brill S et al (2020) Israel ad hoc COVID 19 committee. Guidelines for care of older persons during a pandemic. J Am Geriatr Soc. https://doi.org/10.1111/jgs.16554

31. Rivett L, Sridhar S, Sparkes D et al (2020) Screening of healthcare workers for SARS-CoV-2 highlights the role of asymptomatic carriage in COVID-19 transmission. Elife. https://doi.org/10.7554/ eLife. 58728

32. Canova V, Lederer Schläpfer H, Piso RJ et al (2020) Transmission risk of SARS-CoV-2 to healthcare workers -observational results of a primary care hospital contact tracing. Swiss Med Wkly 150:w20257. https://doi.org/10.4414/smw.2020.20257

33. Heinzerling A, Stuckey MJ, Scheuer T et al (2020) Transmission of COVID-19 to Health Care Personnel During Exposures to a Hospitalized Patient Solano County, California, February 2020. MMWR Morb Mortal Wkly Rep 69(15):472-476. https://doi. org/10.15585/mmwr.mm6915e5

34. SIE emergenza COVID. http://www.societaitalianadiendocrin ologia.it/html/cnt/emergenza-covid.asp. Accessed 22 Oct 2020

35. Fascicolo Sanitario Elettronico-Veneto-GDPR. https://salute.regio ne.veneto.it/c/document_library/get_file?uuid=40a059e5-b0b74c3b-9ad7-e797a6d02547\&groupId=533773. Accessed 22 Oct 2020

Publisher's Note Springer Nature remains neutral with regard to jurisdictional claims in published maps and institutional affiliations. 